\title{
OPEN Effect of lighting illuminance and colour temperature on mental workload in an office setting
}

\author{
Jiayi Bao ${ }^{1,2}$, Xinbo Song ${ }^{3 凶}$, Yan $\mathrm{Li}^{1,2}$, Yinjie Bai ${ }^{1,2}$ \& Qianxiang Zhou ${ }^{1,2}$
}

The mental workload of subjects was tested under different lighting conditions, with colour temperatures ranging from 3000 to $6500 \mathrm{~K}$ and illuminance ranging from 300 to $1000 \mathrm{~lx}$. We used both psychological and physiological responses for evaluation. The former was based on NASA Task Load Index (NASA-TLX, NASA), and the latter was based on the electroencephalogram (EEG) P3b analysis of event-related potentials using the "oddball" paradigm experimental task. The results show that as illuminance increases, and the response time becomes longer with a colour temperature of $3000 \mathrm{~K}(\mathrm{P}<0.01)$. However, when the colour temperature is set at $6500 \mathrm{~K}$, the response time becomes shorter as the illuminance increases $(\mathrm{P}<0.01)$. P3b amplitudes were significantly affected by colour temperature $(P=0.009)$ and illuminance $(P=0.038)$ levels. The highest amplitudes occurred at $3000 \mathrm{~K}$ and $750 \mathrm{~lx}$, which is consistent with the trend shown by the subjective scale. The data analysis of error rates is not significant. These results suggest that an office environment with a colour temperature of $3000 \mathrm{~K}$ and illumination of $750 \mathrm{~lx}$, which exerts the lowest mental workload, is the most suitable for working. However, the interaction between colour temperature and illuminance in affecting the mental workload of participants is not clear. This work provides more appropriate lighting choices with colour temperature and illuminance to reduce people's mental workload in office settings.

The effects of lighting on health and productivity have raised the level of concern in recent years, as people are spending increasingly more time in artificial light conditions in their everyday lives. Research reports that artificial light has diverse and complex effects on humans, as it affects not only vision but also circadian rhythms ${ }^{1}$. Furthermore, artificial light also impacts migraines ${ }^{2}$, physiological activity levels ${ }^{3}$, mood $^{4}$, etc.

Illuminance and colour temperature are two indicators that can be controlled by artificial lighting, and they also affect human physiology and psychology $y^{5,6}$. Illuminance is defined as the luminous flux per square metre, in units of lux (lx). The colour temperature of a lamp equals the thermal temperature that an idealized black body would be required to assume in order to produce the same colour as the lamp, in units of $\mathrm{K}^{7}$. Kruithof proposed a diagram that defined comfortable lighting conditions by combining illuminance and correlated colour temperature ${ }^{8}$. He indicated that illuminance and colour temperature have an interactive effect on comfort; thus, through the diagram, we could obtain comfortable illuminance ranges at different colour temperatures. Even though there is not enough evidence to support his study, the idea is regarded as pioneering in the field of lighting characteristics. Based on Kruithof's diagram, much research has been carried out, which has been focused on adjusting the range of comfortable lighting conditions. Kakitsuba suggested a new diagram of comfortable lighting illuminance and colour temperature based on psychological and physiological responses ${ }^{9}$. The authors used this research method to further analyze the responses of different genders to the comfort of LED lighting ${ }^{10}$. In addition, as a physiological response, electroencephalogram (EEG) is often used to study the effect of light conditions on cognition ${ }^{11-16}$.

Mental workload is the amount of processing capacity that a participant needs to perform a task in a given time ${ }^{17}$. Attention and memory tasks were chosen as the cognitive tasks in the present study, given that attention is one of the most fundamental features of our conscious performance in daily life ${ }^{18,19}$. Among different aspects of attention, sustained attention tasks are closely related to office work and can induce brain electrical activity. Sustained attention involves the ability to maintain concentration on continuous tasks or information sources ${ }^{20,21}$. Thakral et al. and Lee et al. demonstrated that sustained attention influences neural activity in the parietal brain region $^{22,23}$. An uncomfortable working environment can lead to cognitive fatigue and reduced work performance, thereby increasing the mental workload under conditions of sustained attention ${ }^{24}$.

${ }^{1}$ School of Biological Science and Medical Engineering, Beihang University, Beijing 100191, China. ${ }^{2}$ Beijing Advanced Innovation Centre for Biomedical Engineering, Beihang University, Beijing 100191, China. ${ }^{3}$ Beijing Aeronautical Technology Research Center, Beijing 100076, China. ${ }^{\varpi}$ email: bjy5700@163.com 


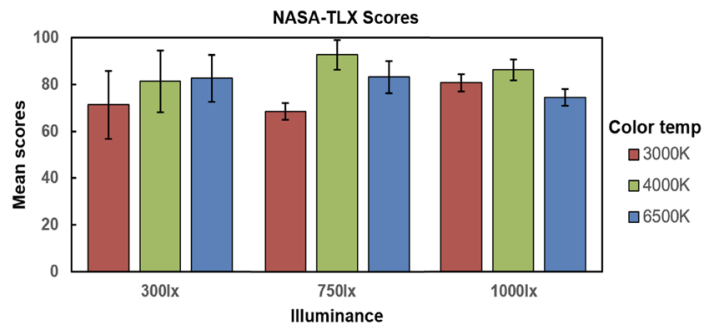

Figure 1. NASA-TLX scores (mean $\pm \mathrm{SD}$ ) under different conditions of colour temperatures $(3000 \mathrm{~K} / 4000 \mathrm{~K} / 6500 \mathrm{~K})$ and illuminance $(300 \mathrm{~lx} / 750 \mathrm{~lx} / 1000 \mathrm{~lx})$ levels. There was no significant main effect result for either the illuminance or the colour temperature. The interaction effect between illuminance and colour temperatures was also not significant.

\begin{tabular}{|l|l|l|l|l|}
\hline Colour temperature $(\mathbf{K})$ & Illuminance $(\mathbf{l x})$ & Scores $^{\mathbf{a}}$ & $\mathbf{R e}-$ time $^{\mathbf{b}}$ & ${\text { P3b-amp }(\boldsymbol{\mu v})^{\mathbf{c}}}^{\mathbf{c}}$ \\
\hline 3000 & 300 & $71.4 \pm 14.55$ & $0.12 \pm 0.10$ & $0.83 \pm 0.30$ \\
\hline 3000 & 750 & $68.6 \pm 13.18$ & $0.40 \pm 0.22$ & $1.67 \pm 0.31$ \\
\hline 3000 & 1000 & $80.9 \pm 10.00$ & $0.52 \pm 0.24$ & $1.12 \pm 0.32$ \\
\hline 4000 & 750 & $92.7 \pm 6.36$ & $0.47 \pm 0.18$ & $1.25 \pm 0.36$ \\
\hline 6500 & 750 & $83.2 \pm 4.55$ & $0.65 \pm 0.14$ & $0.51 \pm 0.18$ \\
\hline
\end{tabular}

Table 1. An example of means \pm SD from physiological and psychological response analysis under different lighting conditions. ${ }^{a}$ NASA-TLX scores as psychological response; lower scores predicted lower mental workload. ${ }^{\mathrm{b}}$ The min-max-normalized response time; shorter re-time predicted lower mental workload. ${ }^{\mathrm{c}} \mathrm{P} 3 \mathrm{~b}$ amplitude of the P4 electrode; higher P3b - amp predicted lower mental workload.

The evaluation method of mental workload includes three aspects: subjective assessment, objective performance, and event-related potential (ERP) analysis. The NASA Task Load Index (NASA-TLX, NASA) is one of the most effective measures of perceived mental workload for subjective assessment. It provides a workload index ranging from 0 to 100 based on six related sources of workload: mental demand, physical demand, temporal demand, performance, effort, and frustration ${ }^{25}$. Thus the subject's response time and error rate to complete the task are evaluated as objective performance. ERP refers to EEG voltage fluctuations related to physical or mental occurrences over time ${ }^{26}$. The P300 ERP is the maximum positive deflection of the EEG signal that occurs approximately $300 \mathrm{~ms}$ after the subject pays attention to the stimulation, including P3a and P3b components ${ }^{27}$. Amplitude (in $\mu \mathrm{v}$ ) and latency (in $\mathrm{ms}$ ) have received widespread attention as evaluations of mental workload ${ }^{28}$. There are many reports that have studied the relationship between P3b component and mental workload through the oddball paradigm ${ }^{29,30}$. It has been reported that the amplitude of P3b decreases with an increase in mental workload ${ }^{29,31,32}$, and its latency increases with an increase in mental workload ${ }^{30,33}$.

In previous studies, the effects of colour temperature on sustained attention have been measured using various tasks, such as word repetition ${ }^{34}$, the Chu Attention Test ${ }^{35}$, short-term memory recall ${ }^{36}$, the Paced Visual Serial Addition Task ${ }^{37}$, and the Numerical Verification Task ${ }^{38,39}$. It has been shown that lighting with warmwhite colour temperature usually results in better cognitive performance. Chellappa demonstrated that higher colour temperature is associated with faster reaction times in attention-related tasks ${ }^{37}$. Kocaoğlu found that $4000 \mathrm{~K}$ significantly increases the number of errors, while $6500 \mathrm{~K}$ is more appropriate for university learning environments $^{40}$. In addition, Min reported that higher illuminance conditions (700 lx) markedly led to lower parietal tonic EEG alpha activity and longer reaction times, than other illuminance conditions $(150 \mathrm{~lx})^{41}$. Lowlevel illuminance often contributes to higher performance appraisals and a better long-term memory rate ${ }^{42,43}$, while high-level illuminance tends to make people less sleepy and more energetic ${ }^{44}$.

However, there is little information in the existing reports about the effect of combinations of illuminance and colour temperature on mental workload. Therefore, we hypothesized that there exists an interaction between illumination and colour temperature that affects mental workload as well as lighting comfort. In addition, the effect of colour temperature and illuminance on mental workload may be nonlinear, but there is a suitable range for relatively low mental workload. The purpose of the present study was to investigate the effects of illuminance and colour temperature on mental workload by EEG and to find appropriate lighting conditions for office environments.

\section{Results}

Subjective assessments. The NASA-TLX scores of different lighting conditions are described in Fig. 1. The higher the score is, the greater the mental workload is ${ }^{45}$. The lowest score was obtained at the colour temperature of $3000 \mathrm{~K}$ and illuminance of $750 \mathrm{~lx}$. However, there was no significant main effect result for either the illuminance or the colour temperature and the interaction effect between illuminance and colour temperatures was also not significant. A portion of the mean subjective scores are shown in Table 1. 

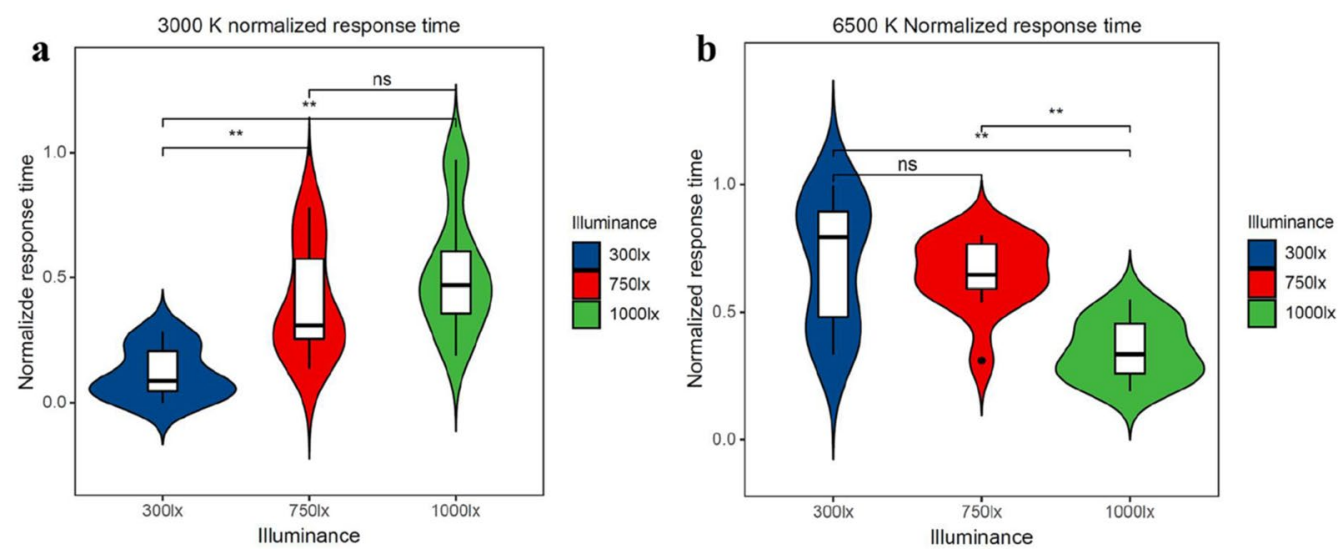

Figure 2. (a) The min-max-normalized response time of the experimental task under different illuminances at $3000 \mathrm{~K}$. (b) The min-max-normalized response time of the experimental task under different illuminances at $6500 \mathrm{~K}$. The upper diagram shows that the response times of 3000-300 lx and 6500-1000 lx were significantly lower than others $\left({ }^{\star} \mathrm{P}<0.05 ;{ }^{*} \mathrm{P}<0.01\right)$.

\begin{tabular}{|l|l|l|l|}
\hline Source & Dependent variable & F & Sig \\
\hline \multirow{4}{*}{ Corrected model } & C3 amplitude & 2.334 & .031 \\
\cline { 2 - 4 } & PZ amplitude & 2.222 & .039 \\
\cline { 2 - 4 } & CP4 amplitude & 2.348 & .030 \\
\hline Colour temperature $\times$ illuminance & C3 amplitude & 2.501 & .053 \\
\hline \multirow{3}{*}{ Colour temperature } & C3 amplitude & 3.191 & .049 \\
\cline { 2 - 4 } & PZ amplitude & 3.970 & .025 \\
\cline { 2 - 4 } & CP4 amplitude & 5.102 & .009 \\
\hline Illuminance & P4 amplitude & 3.478 & .038 \\
\hline
\end{tabular}

Table 2. Significance analysis of the influence of colour temperature and illuminance on P3b amplitude.

Behavioural performance. The average response time and the accuracy rate in the oddball experimental task were analysed. The accuracy rate was not significantly influenced by illuminance or colour temperature. Moreover, the response time was significantly influenced by the illuminance according to the min-max normalization scores. As shown in Fig. 2a,b, as illuminance increases, the response time becomes longer with a colour temperature of $3000 \mathrm{~K}(\mathrm{P}<0.01)$. However, when the colour temperature is set at $6500 \mathrm{~K}$, the response time becomes shorter as illuminance increases $(\mathrm{P}<0.01)$.

Physiological measurements. The amplitude and latency of P3b with different combinations of colour temperature and illuminance were analysed. Latency was not significantly influenced by illuminance or colour temperature. There was no significant interaction between these factors regarding P3b latency. For $\mathrm{P} 3 \mathrm{~b}$ amplitude, the analysis of variance on some electrode sites is listed in Table 2 . The results indicate that amplitude is significant for the colour temperature $(\mathrm{F}[2,22]=5.102, \mathrm{P}=0.009$ at $\mathrm{CP} 4)$ and illuminance levels $(\mathrm{F}[2,22]=3.478, \mathrm{P}=0.038$ at $\mathrm{P} 4)$. However, no interaction of colour temperature and illuminance levels was observed $(\mathrm{F}[4,44]=2.501, \mathrm{P}=0.053)$.

Examples of P3b amplitudes with different colour temperatures under $750 \mathrm{~lx}$ illuminance are presented in Fig. 3, and the grand average waveforms of $\mathrm{P} 3 \mathrm{~b}$ at the CP4 electrode and the scalp topographic distributions are described in Fig. 4. In the case of $750 \mathrm{~lx}$, the results show that the P3b amplitude at CP4 is obviously higher at $3000 \mathrm{~K}$ than at $4000 \mathrm{~K}(\mathrm{P}=0.047)$ or $6500 \mathrm{~K}(\mathrm{P}=0.001)$, meaning that the lowest mental workload occurs at $3000 \mathrm{~K}$.

Examples of P3b amplitudes with different illuminance levels under $3000 \mathrm{~K}$ colour temperature are displayed in Fig. 5, and the grand average waveforms of $\mathrm{P} 3 \mathrm{~b}$ at the $\mathrm{P} 4$ electrode and the scalp topographic distributions are described in Fig. 6. In the case of $3000 \mathrm{~K}$, the results show that the P3b amplitude at $\mathrm{P} 4$ is significantly higher at $750 \mathrm{~lx}$ than at $300 \mathrm{~lx}(\mathrm{P}=0.001)$ or $1000 \mathrm{~lx}(\mathrm{P}=0.001)$, meaning that the lowest mental workload occurs at $750 \mathrm{~lx}$. The means \pm SD of $\mathrm{P} 3 \mathrm{~b}$ amplitudes at $3000 \mathrm{~K}$ are listed in Table 1. 


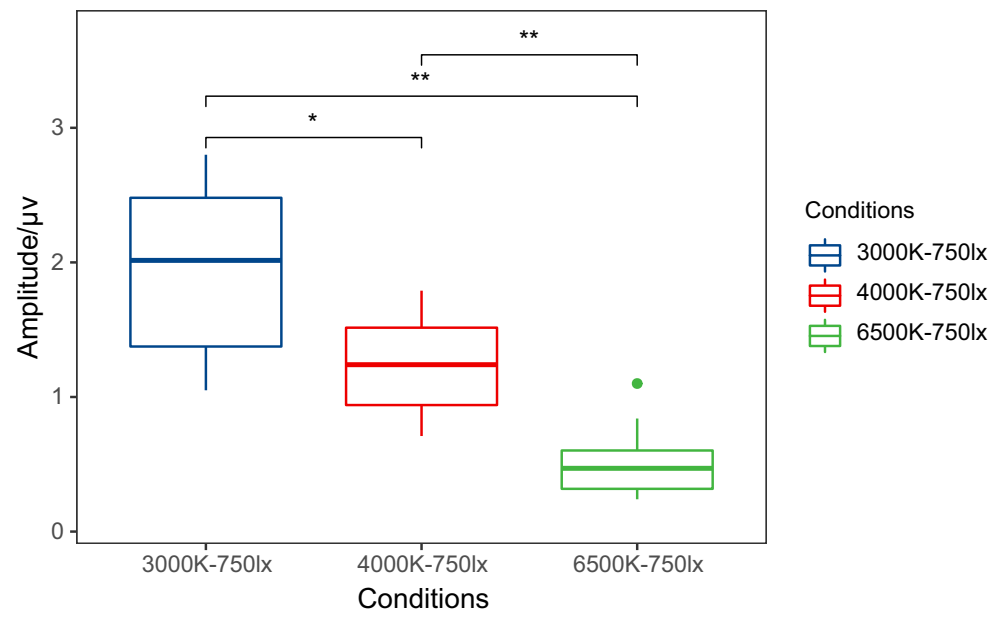

Figure 3. An example of $\mathrm{P} 3 \mathrm{~b}$ amplitudes with different colour temperatures under $750 \mathrm{~lx}$ illuminance at the $\mathrm{CP} 4$ electrode $\left({ }^{\star} \mathrm{P}<0.05 ;{ }^{\star \star} \mathrm{P}<0.01\right)$. The amplitude at $3000 \mathrm{~K}$ was significantly higher, indicating that the lowest mental workload occurred at $3000 \mathrm{~K}$.
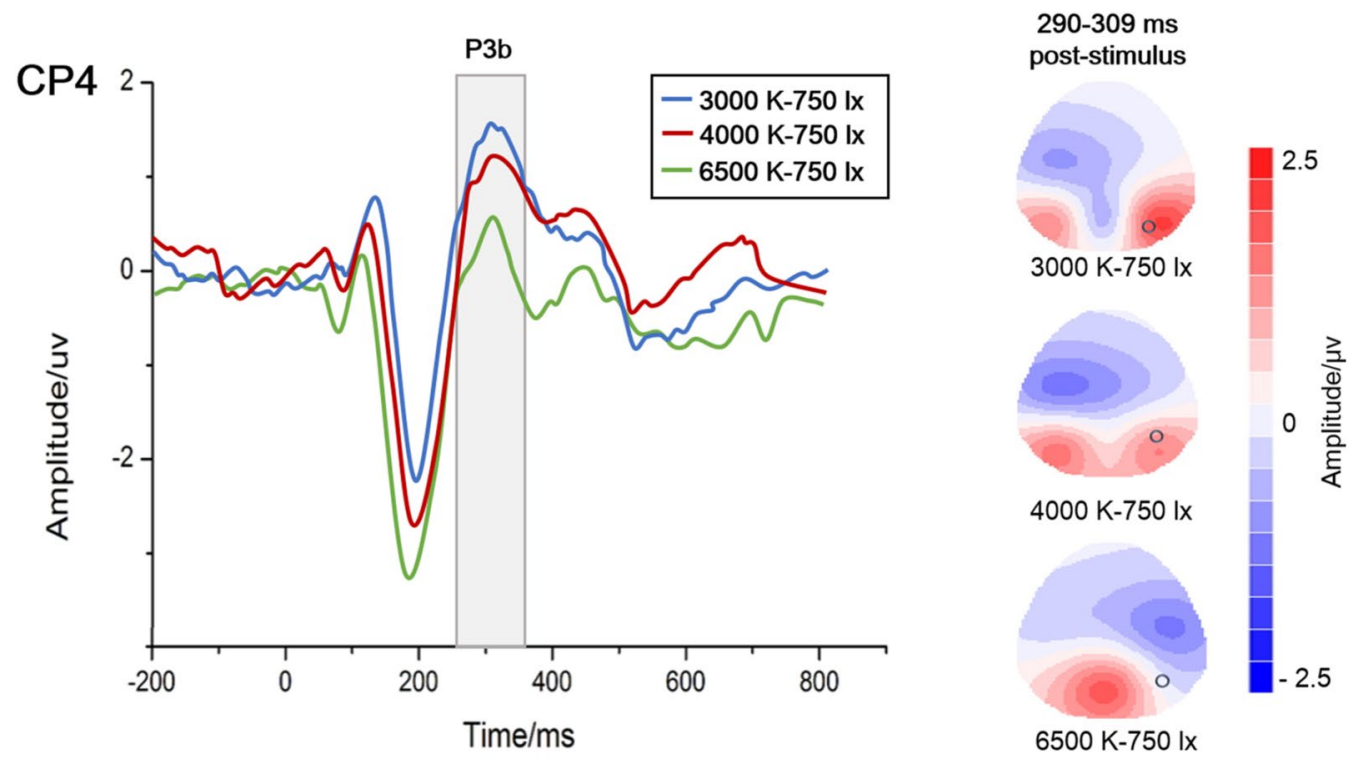

Figure 4. Grand average waveforms of $\mathrm{P} 3 \mathrm{~b}$ at the $\mathrm{CP} 4$ electrode and scalp topographic distributions with different colour temperatures $(3000 \mathrm{~K} / 4000 \mathrm{~K} / 6500 \mathrm{~K})$ under $750 \mathrm{~lx}$ illuminance. The shaded box shows a significant difference in $\mathrm{P} 3 \mathrm{~b}$ waves. And the circles at topographic maps represent the CP4 electrode when P3b occurred near $300 \mathrm{~ms}$.

\section{Discussion}

The effect of lighting illuminance and colour temperature on mental workload was investigated in the present study by subjective assessment, behavioral performance, and EEG analysis. However, no significant interaction between illuminance and colour temperature on mental workload was found from all aspects of the data, as outlined in Table 2. These results are not consistent with the hypothesis that there would be an interaction between illumination and colour temperature on mental workload, as well as lighting comfort.

Neither illuminance level nor colour temperature shown a significant effect on NASA-TLX scores. The principal reason may be individual differences and the limited sample size.

As indicated in Fig. 2a,b, when the colour temperature is set at $3000 \mathrm{~K}$, the response time will be delayed as the illuminance increases, which is consistent with the findings of a previous study ${ }^{41}$. Yan et al. also found that learning efficiency was higher at a $2700 \mathrm{~K}$ colour temperature and $300 \mathrm{~lx}$ illuminance ${ }^{46}$. However, the response time becomes shorter as the illuminance increases when the colour temperature is set at $6500 \mathrm{~K}$. We consider $6500 \mathrm{~K}$, which is called a "cool temperature", to make people more alert and better able to concentrate when 


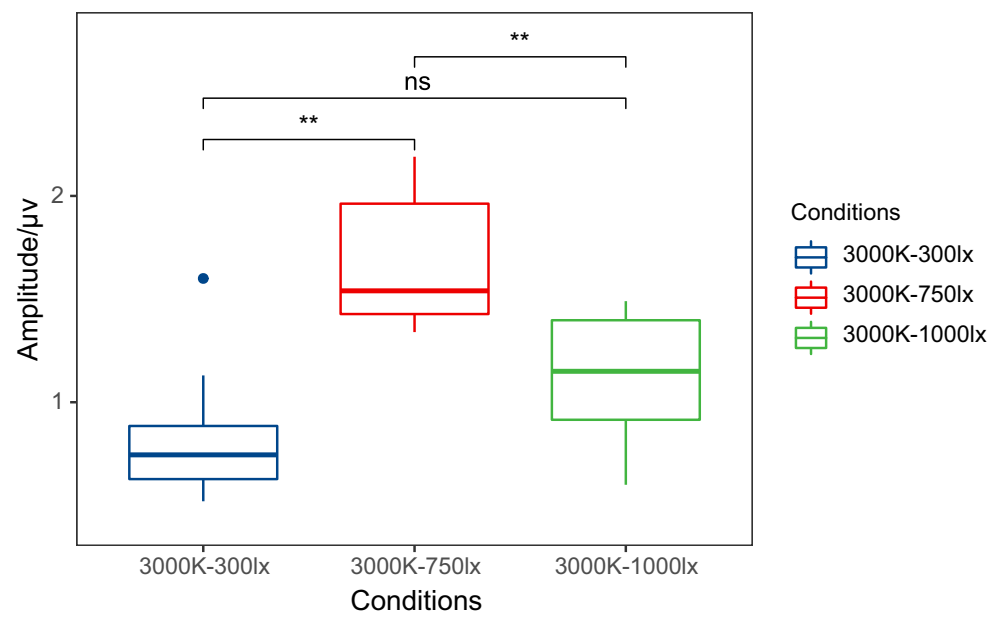

Figure 5. An example of $\mathrm{P} 3 \mathrm{~b}$ amplitudes with different illuminance levels under $3000 \mathrm{~K}$ colour temperature at the $\mathrm{P} 4$ electrode $\left({ }^{\star} \mathrm{P}<0.05 ;{ }^{*} \mathrm{P}<0.01\right)$. The amplitude at $750 \mathrm{~lx}$ was significantly higher, indicating that the lowest mental workload occurred at $750 \mathrm{~lx}$.
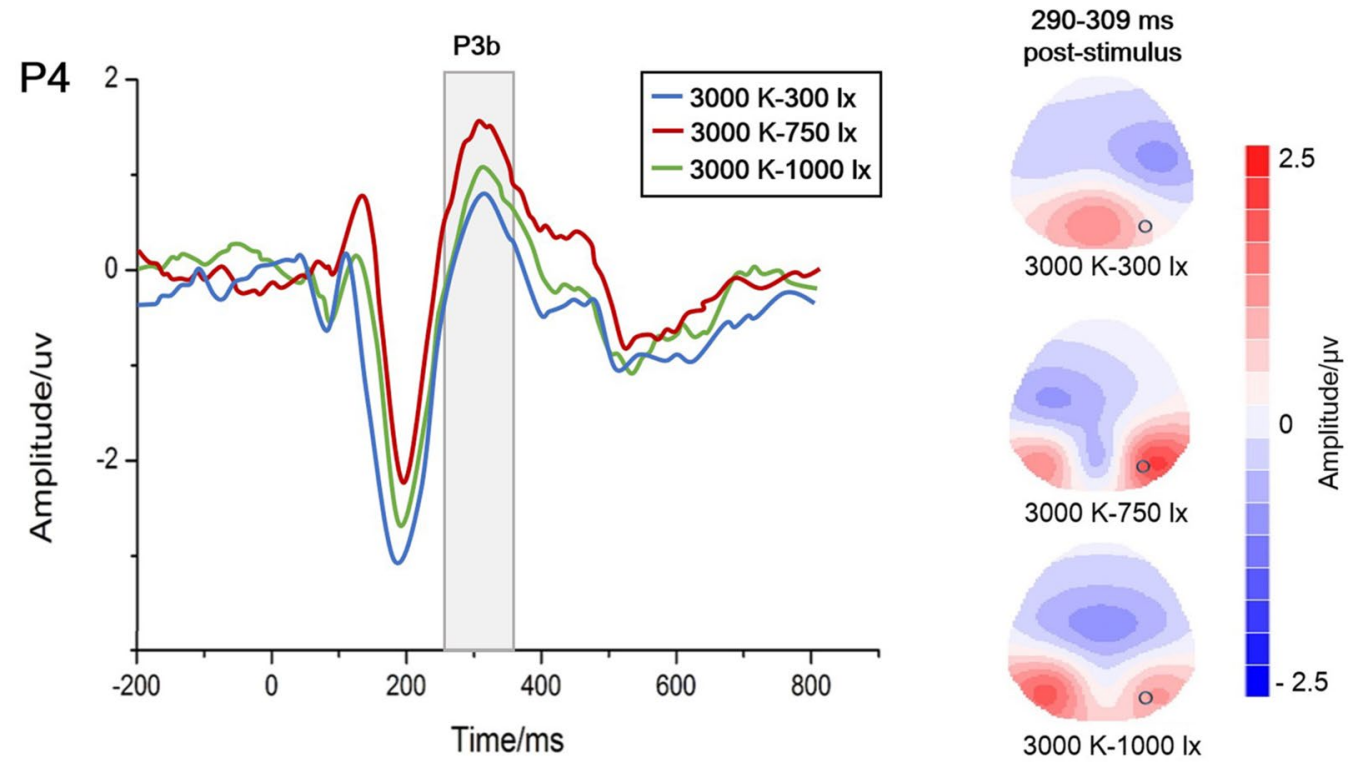

Figure 6. Grand average waveforms of $\mathrm{P} 3 \mathrm{~b}$ at the $\mathrm{P} 4$ electrode and scalp topographic distributions with different illuminance levels (300 lx/750 lx/1000 lx) under $3000 \mathrm{~K}$ colour temperature. The shaded box shows a significant difference in $\mathrm{P} 3 \mathrm{~b}$ waves. And the circles at topographic maps represent the $\mathrm{P} 4$ electrode when $\mathrm{P} 3 \mathrm{~b}$ occurred near $300 \mathrm{~ms}$.

the illuminance improves. Chellappa found that light at $6500 \mathrm{~K}$ led to significantly faster reaction time in the sustained attention task ${ }^{37}$. Li Lan also reported that greater positive moods were expressed at $2000 \mathrm{~lx}, 6000 \mathrm{~K}$ and $300 \mathrm{~lx}, 3000 \mathrm{~K}$ compared to $2000 \mathrm{~lx}, 3000 \mathrm{~K}$ and $300 \mathrm{~lx}, 6000 \mathrm{~K}^{47}$.

For ERP analysis, a significant effect of light conditions on the P3b latency was not observed. The P3b latency represents the time of mental processing, and it is often increased when the classification of evoked stimuli becomes more difficult ${ }^{48}$. There was no change in the difficulty of the categorizing tasks that elicited stimuli in the present study. The P3b amplitude represents the amount of attention given to evoked stimuli ${ }^{49}$. Different light conditions affect people's ability to focus attention on visual tasks through their impact on the visual system ${ }^{50}$. And the amplitude of P3b decreases with an increase in mental workload ${ }^{48}$. As described in Figs. 3 and 5, P3b amplitudes are observably influenced by colour temperature and illuminance. When the illuminance is $750 \mathrm{~lx}$, the highest amplitude occurs at $3000 \mathrm{~K}$. Manav demonstrated that $2700 \mathrm{~K}$ was suggested for 'relaxation' and 'saturation evaluation ${ }^{31}$. This may indicate that approximately $3000 \mathrm{~K}$ is a low mental workload colour temperature. At a colour temperature of $3000 \mathrm{~K}$, the highest amplitude occurs at $750 \mathrm{~lx}$. In either an extremely bright or dark environment, we cannot concentrate and are unable to complete the memory task well. This is the same as the 


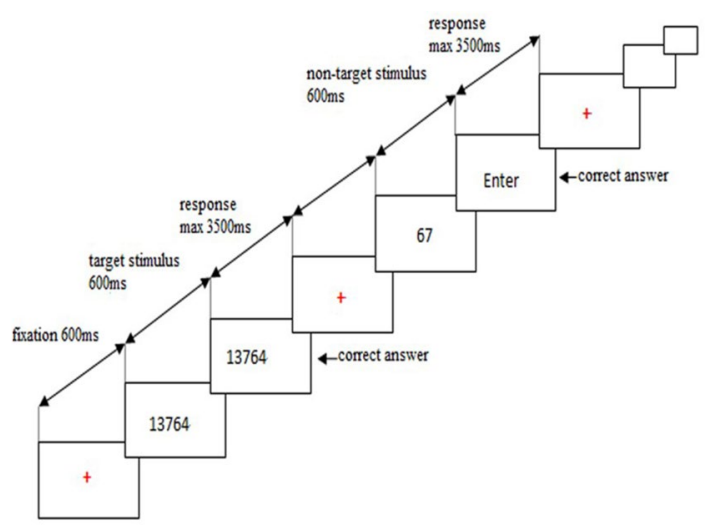

Figure 7. The task flow diagram for a sample stimulus. Stimulus presentation occurred after presentation of a fixation cross.

relationship between arousal and attention. The ability to focus attention effectively is nonlinear with arousal. It is roughly like an inverted $\mathrm{U}$-shaped function ${ }^{52}$. Hancock also reported a similar inverted-U law ${ }^{53}$ and that environmental stressors can transform an individual's adaptability from a stable state to an unstable state. Very low or very high task requirements will reduce adaptability, thereby leading to increased mental workload ${ }^{54}$.

Another purpose of the present study was to find more suitable lighting conditions for the office environment. As described in Table 1, through the analysis of EEG data, a combination of $3000 \mathrm{~K}$ colour temperature and $750 \mathrm{~lx}$ illumination produced the lowest mental workload. This is also consistent with the results of the subjective assessment.

\section{Conclusion}

Under different lighting conditions of colour temperature (3000 K/4000 K/6500 K) and illuminance $(300 \mathrm{~lx} / 750 \mathrm{~lx} / 1000 \mathrm{~lx})$, twelve postgraduates participated in sustained attention task experiments. In addition, NASA-TLX scores as psychological responses, accuracy and response time as behavioral performance, and EEG data as physiological responses were recorded continuously in the experiment. The results show that the combination of $3000 \mathrm{~K}$ colour temperature and $750 \mathrm{~lx}$ illumination, which requires the lowest mental workload, is better suited to office settings. However, no significant interaction between colour temperature and illumiance for mental workload was found.

This study included only for healthy student participants. Vision problems such as myopia, hyperopia, astigmatism, etc. may lead to deviations in test results. More studies with larger sample sizes are needed to test the findings reported here. In addition, compared with the background lighting conditions, the influence of the screen stimulus light on the experimental results may be more remarkable. The issue of how to set the screen lighting condition to minimize its impact on experimental results needs further research.

\section{Methods}

Subjects. Twelve postgraduates from Beihang University participated as subjects for this study. All the participants (male, age: 23-27 years, mean 24.3) were right-handed and possessed normal vision. Caffeinated drinks, medication, smoking, and exercise were prohibited before the experiment for one week. Meanwhile, all the participants reported that they slept between six and eight hours the night before the study. The experimental protocol was approved by the Ethics Committee of Beihang University, and all methods were carried out in accordance with relevant guidelines and regulations. All research activities adhered to the principles of the Declaration of Helsinki, and written informed consent was obtained from the participants before the experiment.

Cognitive task. A computerized task was chosen for this experiment because office workers under artificial lighting obtain the majority of their information from display terminals. The experimental task was a modified "oddball" paradigm controlled by E-prime software (Psychology Software Tools, Inc., Pittsburgh, PA) that placed demands on sustained attention and memory. In this task, the target stimulus was a five-digit number, and the non-target stimulus was a two-digit number. Each block contained 120 target stimuli and 480 non-target stimuli. Between every two target stimuli, there were approximately two to six non-target stimuli. The presentation time for each stimulus was $600 \mathrm{~ms}$, and $3.5 \mathrm{~s}$ were allowed for responding stimulus. The task flow diagram is shown in Fig. 7. In the task flow, the start signal occurs in the middle of the computer screen. The '+' signal means you should focus, and the sequences of numbers take place in the center of the screen. The image used in the current study was $1280 \times 1024$ pixels.

Each experimental block corresponding to one illuminance and colour temperature combination took approximately $25 \mathrm{~min}$. Subjects were instructed to memorize each target stimulus number as soon as possible. Then, they were required to enter the number on a form after it disappeared on the computer. If a non-target stimulus appeared, the participants were asked to identify it as such and to press the "Enter" button after it disappeared. 


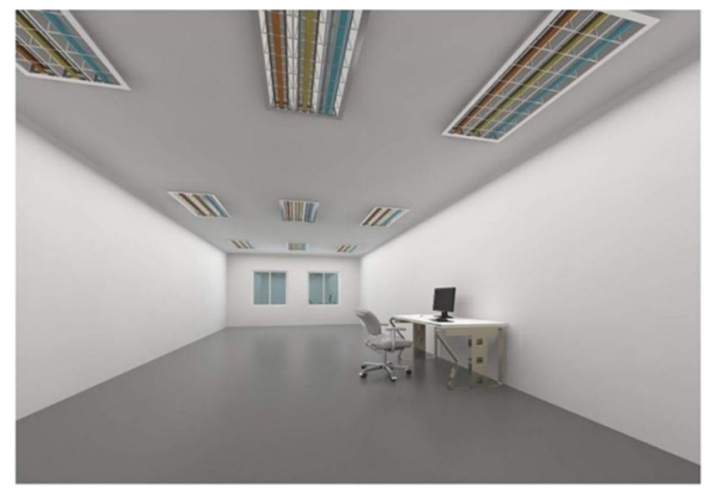

Figure 8. In the laboratory setting, nine controllable luminaires were installed on the ceiling, and black curtains were installed on the windows to block natural sunlight.

Procedure. The experimental office (dimensions: $10 \mathrm{~m} \mathrm{~L} \times 4.5 \mathrm{~m} \mathrm{~W} \times 3.0 \mathrm{~m} \mathrm{H}$ ) is shown in Fig. 8. The air temperature was approximately $25^{\circ} \mathrm{C}$. Black curtains were used to exclude natural sunlight. The suspended ceiling was white. The walls were painted light white, and the floor was light grey brick. The lighting system was supplied by nine luminaires that were recessed in the suspended ceiling. The total number of fluorescent lamps (Philips TLD/36 W/830; Philips TLD/36 W/840; Philips TLD/36 W/865) was 27. Each of them was connected to dimmable electronic ballasts, which were regulated by a Light Master 100 lighting control system. The lighting system was designed to provide nine different lighting scenarios, which were numbered on a remote control. This lighting system could be adjusted to maintain constant illumination levels of 300,750 , and $1000 \mathrm{~lx}$ on the working surface, while colour temperature of 3000,4000 , and $6500 \mathrm{~K}$ could be created separately. Illuminance values were measured by an LMT PO1704 Luxmeter $(0-99,999 \mathrm{~lx}, \pm 0.01 \mathrm{~lx})$, and colour temperature values were measured by a TES-136 colourimeter $(0-9,999 \mathrm{~K}, \pm 0.02 \mathrm{~K})$. The lighting scenarios in this experiment were in random order to avoid any influence of the sequence. Each experiment consisted of nine trials of $25 \mathrm{~min}$ each, followed by breaks of $30 \mathrm{~min}$ i.e., enough time for rest and adaptation to the new illumination.

The target stimulus was presented on a PC (Lenovo) screen in front of the participant. In this task, all the participants were required to practice the task until they were skilled at it, or rather when their accuracy rate was $80 \%$ or more. The participants were required to focus, to do their best to complete the task as fast as possible, and to ensure the accuracy of their answers. A small reward was given for good performance. During the experiment, the participants' response times and accuracy rates were recorded by E-prime.

All the participants had $30 \mathrm{~min}$ to adapt to the new environment. After that, the participants needed to accomplish the task block. Each subject should complete the NASA-TLX after each block, which was used to evaluate mental workload regarding participants' subjective feelings. The experiments were conducted from 08:00 to 11:30 and from 14:00 to 18:30. The participants could finish the task in $30 \mathrm{~min}$ and rest for $30 \mathrm{~min}$.

EEG data recording and processing. EEG was recorded by $32 \mathrm{Ag} / \mathrm{AgCl}$ electrodes with the international $10 / 20$ system layout mounted in an elastic cap (Easycap, Germany). The signals were recorded by NeuroScan SynAmps amplifiers and Curry 7.0 software (Compumedics NeuroScan, Charlotte, NC), with a $1000 \mathrm{~Hz}$ sampling rate. The impedances of all electrodes were kept below $5 \mathrm{k} \Omega$. The reference electrode was $\mathrm{FCz}$, and the ground electrode was placed on the forehead ${ }^{55}$. Additional electrodes were placed at the outer left canthus and below the left eye to measure electrooculography (EOG) activity with a bipolar recording.

EEG data preprocessing was conducted by Curry 7.0 software. The EEG data were first re-referenced to an average of bilateral mastoids, and the bandpass filter was from 0.1 to $30 \mathrm{~Hz}$. Epochs of $1000 \mathrm{~ms}$ were obtained for each trial starting $200 \mathrm{~ms}$ before the target stimulus onset and ending $800 \mathrm{~ms}$ after. A baseline correction was applied (baseline - 200 to $0 \mathrm{~ms}$ ). A correction algorithm was applied to remove eye movement artefacts (e.g., eye blinks, muscle artefacts) ${ }^{56}$.

P3b analysis. In the following we focused on the P3b component elicited by the target stimuli. P3b amplitude and latency were used to infer mental workload under different conditions of colour temperature and illumination. The mean amplitude and latency were calculated at electrode sites $(\mathrm{C} 3, \mathrm{Cz}, \mathrm{C} 4, \mathrm{CP} 3, \mathrm{CPz}, \mathrm{CP} 4, \mathrm{P} 3$, $\mathrm{Pz}$, and $\mathrm{P} 4)$.

Statistics analysis. All variables were first tested for normality with Shapiro-Wilk tests ${ }^{57}$, and all variables followed a normal distribution. Then, the data were analysed with a repeated measures analysis of variance (ANOVA), which included two within-subjects factors (illuminance: $300 \mathrm{~lx} / 750 \mathrm{~lx} / 1000 \mathrm{~lx}$, colour temperature: $3000 \mathrm{~K} / 4000 \mathrm{~K} / 6500 \mathrm{~K}$ ). The means were compared by Duncan's test at a probability of $95 \%$. Statistical analyses were performed using SPSS Statistics 17.0 (SPSS, Inc., Chicago, IL, USA). Because of limited numbers of participants, individual differences influenced the raw results. To reduce this influence, the min-max normalization data standardization method that transferred the value of data to a range of $[0,1]^{58}$ was used to analyse the NASA-TLX and behavioral performance data. 


\section{Data availability}

The data that support the findings of this study are available from the corresponding author upon reasonable request.

Received: 18 April 2021; Accepted: 16 July 2021

Published online: 27 July 2021

\section{References}

1. Stevens, R. G., Blask, D. E., Brainard, G. C., Hansen, J., Lockley, S. W., Provencio, I., \& Reinlib, L. Meeting report: The role of environmental lighting and circadian disruption in cancer and other diseases. Environ. Health Perspect. 115(9), 1357-1362. https:// doi.org/10.1289/ehp.10200 (2007).

2. Boyce, P. R. The impact of light in buildings on human health. Indoor Built Environ. 19(1), 8-20. https://doi.org/10.1177/14203 26X09358028 (2010).

3. Saito, Y. et al. Effect of bright light exposure on muscle sympathetic nerve activity in human. Neurosci. Lett. 219(2), 135-137. https://doi.org/10.1016/S0304-3940(96)13171-2 (1996).

4. Fernandez, D. C. et al. Light affects mood and learning through distinct retina-brain pathways. Cell 175(1), 71-84. https://doi.org/ 10.1016/j.cell.2018.08.004 (2018)

5. Taniguchi, Y., Miki, M., Hiroyasu, T., \& Yoshimi, M. Preferred illuminance and colour temperature in creative works. in 2011 IEEE International Conference on Systems, Man, and Cybernetics 3255-3260. https://doi.org/10.1109/ICSMC.2011.6084171 (IEEE, 2011).

6. Miki, M., Ikegam, H., Motoya, Y., \& Fujimoto, S. Combination of preferred illuminance and preferred colour temperature for work. in 2013 IEEE International Conference on Systems, Man, and Cybernetics 4577-4582. https://doi.org/10.1109/SMC.2013.779 (IEEE, 2013).

7. Wessolowski, N., Koenig, H., Schulte-Markwort, M. \& Barkmann, C. The effect of variable light on the fidgetiness and social behavior of pupils in school. J. Environ. Psychol. 39, 101-108. https://doi.org/10.1016/j.jenvp.2014.05.001 (2014).

8. Kruithof, A. A. Tubular luminescence lights for general illumination. Philips Tech. Rev. 6(3), 65-96 (1941).

9. Kakitsuba, N. Comfortable indoor lighting conditions evaluated from psychological and physiological responses. Leukos 12(3), 163-172. https://doi.org/10.1080/15502724.2015.1061945 (2016).

10. Kakitsuba, N. Comfortable indoor lighting conditions for LEDlights evaluated from psychological and physiological responses. Appl. Ergon. 82, 102941. https://doi.org/10.1016/j.apergo.2019.102941 (2020).

11. Ermolaev, R. Y. \& Kleinman, D. The effect of background illumination on pattern onset visual evoked potentials. Electroencephalogr. Clin. Neurophysiol. 55(5), 546-556. https://doi.org/10.1016/0013-4694(83)90165-7 (1983).

12. Yagi, A., Imanishi, S. \& Konishi, H. Brain potentials associated with eye fixations during visual tasks under different lighting systems. Ergonomics 41(5), 670-677. https://doi.org/10.1080/001401398186838 (1998).

13. Noguchi, H. \& Sakaguchi, T. Effect of illuminance and colour temperature on lowering of physiological activity. Appl. Hum. Sci. 18(4), 117-123. https://doi.org/10.2114/jpa.18.117 (1999).

14. Maher, A. M. et al. Effect of luminance level on electro-encephalogram alpha-wave synchronisation. Med. Biol. Eng. Comput. 39(6), 672-677. https://doi.org/10.1007/bf02345440 (2001).

15. Shin, J. Y., Chun, S. Y., \& Lee, C. S. Analysis of the effect on attention and relaxation level by correlated colour temperature and illuminance of LED lighting using EEG signal. J. Korean Inst. Illumin. Electr. Install. Eng. 27(5). https://doi.org/10.5207/JIEIE.2013. 27.5.009 (2013).

16. Park, J. Y., Min, B. K., Jung, Y. C., Pak, H., Jeong, Y. H., \& Kim, E. Illumination influences working memory: An EEG study. Neuroscience 247, 386-394. https://doi.org/10.1016/j.neuroscience.2013.05.016 (2013)

17. Gopher, D., \& Donchin, E. Workload: An examination of the concept. in Handbook of Perception and Human Performance. Cognitive Processes and Performance (Boff, K. R., Kaufman, L. \& Thomas, J. P. Eds.). Vol. 2. 1-49. (1986).

18. Sohlberg, M. M., \& Mateer, C. A. Introduction to Cognitive Rehabilitation: Theory and Practice. https://doi.org/10.1016/00283932(90)90117-7 (Guilford Press, 1989).

19. Sohlberg, M. M., \& Mateer, C. A. (Eds.). Cognitive Rehabilitation: An Integrative Neuropsychological Approach. https://doi.org/10. 1093/brain/awg003 (Guilford Press, 2001).

20. Cimprich, B. A theoretical perspective on attention and patient education. Adv. Nurs. Sci. 14(3), 39-51. https://doi.org/10.1097/ 00012272-199203000-00007 (1992).

21. Solso, R. L., MacLin, M. K., \& MacLin, O. H. Cognitive Psychology, 7th edn. https://psycnet.apa.org/record/2004-19852-000 (Pearson Education New Zealand, 2005).

22. Thakral, P. P. \& Slotnick, S. D. The role of parietal cortex during sustained visual spatial attention. Brain Res. 1302, 157-166. https:// doi.org/10.1016/j.brainres.2009.09.031 (2009).

23. Lee, J., Ku, J., Han, K., Park, J., Lee, H., Kim, K. R. \& Kim, S. I. rTMS over bilateral inferior parietal cortex induces decrement of spatial sustained attention. Front. Hum. Neurosci. 7, 26. https://doi.org/10.3389/fnhum.2013.00026 (2013).

24. Subramanyam, M., Muralidhara, P., \& Pooja, M. Mental workload and cognitive fatigue: A study. IUP J. Manag. Res. 12(2). https:// doi.org/10.2478/BF02475910 (2013).

25. Finomore, V. S., Warm, J. S., Matthews, G., Riley, M. A., Dember, W. N., Shaw, T. H., \& Scerbo, M. W. Measuring the workload of sustained attention. in Proceedings of the Human Factors and Ergonomics Society Annual Meeting Vol. 50(16) 1614-1618. https:// doi.org/10.1177/154193120605001621 (SAGE Publications, 2006).

26. Picton, T. W., Bentin, S., Berg, P., Donchin, E., Hillyard, S. A., Johnson Jr, R., \& Taylor, M. J. Guidelines for using human eventrelated potentials to study cognition: Recording standards and publication criteria. Psychophysiology 37(2), 127-152. https://doi. org/10.1111/1469-8986.3720127 (2000).

27. de Tommaso, M., Betti, V., Bocci, T., Bolognini, N., Di Russo, F., Fattapposta, F., \& Valeriani, M. Pearls and pitfalls in brain functional analysis by event-related potentials: A narrative review by the Italian Psychophysiology and Cognitive Neuroscience Society on methodological limits and clinical reliability-Part I. Neurol. Sci. 1-25 (2020).

28. Marucci, M., Di Flumeri, G., Borghini, G., Sciaraffa, N., Scandola, M., Pavone, E. F., \& Aricò, P. The impact of multisensory integration and perceptual load in virtual reality settings on performance, workload and presence. Sci. Rep. 11(1), 1-15. https://doi. org/10.1038/s41598-021-84196-8 (2021).

29. Novak, G. P., Ritter, W., Vaughan, H. G. Jr. \& Wiznitzer, M. L. Differentiation of negative event-related potentials in an auditory discrimination task. Electroencephalogr. Clin. Neurophysiol. 75(4), 255-275. https://doi.org/10.1016/0013-4694(90)90105-S (1990).

30. Horat, S. K. et al. Assessment of mental workload: A new electrophysiological method based on intra-block averaging of ERP amplitudes. Neuropsychologia 82, 11-17. https://doi.org/10.1016/j.neuropsychologia.2015.12.013 (2016).

31. Ghani, U., Signal, N., Niazi, I. \& Taylor, D. ERP based measures of cognitive workload: A review. Neurosci. Biobehav. Rev. https:// doi.org/10.1016/j.neubiorev.2020.07.020 (2020).

32. Causse, M., Fabre, E., Giraudet, L., Gonzalez, M. \& Peysakhovich, V. EEG/ERP as a measure of mental workload in a simple piloting task. Proc. Manuf. 3, 5230-5236. https://doi.org/10.1016/j.promfg.2015.07.594 (2015). 
33. Gaál, Z. A., Csuhaj, R. \& Molnár, M. Age-dependent changes of auditory evoked potentials-Effect of task difficulty. Biol. Psychol. 76(3), 196-208. https://doi.org/10.1016/j.biopsycho.2007.07.009 (2007).

34. LaPointe, L. L., Maitland, C. G., Blanchard, A. A., Kemker, B. E., Stierwalt, J. A., \& Heald, G. R. The effects of auditory distraction on visual cognitive performance in multiple sclerosis. J. Neuro-ophthalmol. 25(2), 92-94. https://doi.org/10.1097/01.wno.00001 611660.91272 .18 (2005).

35. Huang, R. H., Lee, L., Chiu, Y. A. \& Sun, Y. Effects of correlated colour temperature on focused and sustained attention under white LED desk lighting. Colour Res. Appl. 40(3), 281-286. https://doi.org/10.1002/col.21885 (2015).

36. Knez, I. \& Hygge, S. Irrelevant speech and indoor lighting: Effects on cognitive performance and self-reported affect. Appl. Cogn. Psychol. 16(6), 709-718. https://doi.org/10.1006/jevp.2001.0222 (2002).

37. Chellappa, S. L. et al. Non-visual effects of light on melatonin, alertness and cognitive performance: Can blue-enriched light keep us alert?. PLoS ONE 6(1), e16429. https://doi.org/10.1371/journal.pone.0016429 (2011).

38. Davis, R. G. \& Garza, A. Task lighting for the elderly. J. Illum. Eng. Soc. 31(1), 20-32 (2002).

39. Yamagishi, M., Yamaba, K., Kubo, C., Nokura, K. \& Nagata, M. Effects of LED lighting characteristics on visual performance of elderly people. Gerontechnology 7(2), 243. https://doi.org/10.4017/GT.2008.07.02.180.00 (2008).

40. Kocaoğlu, R. The Effects of Correlated Colour Temperature on Sustained Attention and Mood of University Students in Learning Environments (Doctoral Dissertation, Bilkent University, 2015).

41. Min, B. K., Jung, Y. C., Kim, E. \& Park, J. Y. Bright illumination reduces parietal EEG alpha activity during a sustained attention task. Brain Res. 1538(22), 83-92. https://doi.org/10.1016/j.brainres.2013.09.031 (2013).

42. Baron, R. A., Rea, M. S. \& Daniels, S. G. Effects of indoor lighting (illuminance and spectral distribution) on the performance of cognitive tasks and interpersonal behaviors: The potential mediating role of positive affect. Motiv. Emot. 16(1), 1-33. https://doi. org/10.1007/BF00996485 (1992).

43. Jung, H. C., Kim, J. H. \& Lee, C. W. The effect of the illuminance of light emitting diode (LED) lamps on long-term memory. Displays 49, 1-5. https://doi.org/10.1016/j.displa.2017.05.001 (2017).

44. Smolders, K. C., De Kort, Y. A. \& Cluitmans, P. J. M. A higher illuminance induces alertness even during office hours: Findings on subjective measures, task performance and heart rate measures. Physiol. Behav. 107(1), 7-16. https://doi.org/10.1016/j.physb eh.2012.04.028 (2012).

45. Hart, S. G., \& Staveland, L. E. Development of NASA-TLX (Task Load Index): Results of empirical and theoretical research. in Advances in Psychology Vol. 52 139-183. https://doi.org/10.1016/S0166-4115(08)62386-9 (North-Holland, 1988).

46. Yong-hong, Y. A. N., Ning, Y. A. N., Yang, G. U. A. N., \& Heng-zhi, Z. E. N. G. Impact on brain wave rhythm and learning efficiency by colour temperature of artificial light sources. J. Civ. Architect. Environ. Eng. 1, 76-79. https://doi.org/10.11835/j.issn.1674-4764. 2012.01.015 (2015).

47. Lan, L., Hadji, S., Xia, L., \& Lian, Z. The effects of light illuminance and correlated colour temperature on mood and creativity. in Building Simulation Vol. 14(3) 463-475. https://doi.org/10.1007/s12273-020-0652-z (Tsinghua University Press, 2021).

48. Käthner, I., Wriessnegger, S. C., Müller-Putz, G. R., Kübler, A. \& Halder, S. Effects of mental workload and fatigue on the P300, alpha and theta band power during operation of an ERP (P300) brain-computer interface. Biol. Psychol. 102, 118-129. https:// doi.org/10.1016/j.biopsycho.2014.07.014 (2014).

49. Dyke, F. B., Leiker, A. M., Grand, K. F., Godwin, M. M., Thompson, A. G., Rietschel, J. C., \& Miller, M. W. The efficacy of auditory probes in indexing cognitive workload is dependent on stimulus complexity. Int. J. Psychophysiol. 95(1), 56-62. https://doi.org/ 10.1016/j.ijpsycho.2014.12.008 (2015).

50. Lee, C. W., \& Kim, J. H. The influence of LED lighting on attention and long-term memory. Int. J. Opt. https://doi.org/10.1155/ 2020/8652108 (2020).

51. Manav, B. An experimental study on the appraisal of the visual environment at offices in relation to colour temperature and illuminance. Build. Environ. 42(2), 979-983. https://doi.org/10.1016/j.buildenv.2005.10.022 (2007).

52. Purves, D. et al. Cognitive Neuroscience (Sinauer Associates, Inc., 2008).

53. Hancock, P. A. A dynamic model of stress and sustained attention. Hum. Factors 31(5), 519-537. https://doi.org/10.1177/00187 2088903100503 (1989)

54. Dehais, F., Lafont, A., Roy, R. \& Fairclough, S. A neuroergonomics approach to mental workload, engagement and human performance. Front. Neurosci. 14, 268. https://doi.org/10.3389/fnins.2020.00268 (2020).

55. Wu, J., Zhou, Q., Li, J., Kong, X. \& Xiao, Y. Inhibition-related N2 and P3: Indicators of visually induced motion sickness (VIMS). Int. J. Ind. Ergon. 78, 102981. https://doi.org/10.1016/j.ergon.2020.102981 (2020).

56. Gratton, G., Coles, M. G. \& Donchin, E. A new method for off-line removal of ocular artifact. Electroencephalogr. Clin. Neurophysiol. 55(4), 468-484. https://doi.org/10.1016/0013-4694(83)90135-9 (1983).

57. Shapiro, S. S. \& Wilk, M. B. An analysis of variance test for normality (complete samples). Biometrika 52(3/4), 591-611. https:// doi.org/10.2307/2333709 (1965)

58. Hassler, A. P., Menasalvas, E., García-García, F. J., Rodríguez-Mañas, L., \& Holzinger, A. Importance of medical data preprocessing in predictive modeling and risk factor discovery for the frailty syndrome. BMC Med. Inform. Decis. Mak. 19(1), 1-17. https://doi. org/10.1186/s12911-019-0747-6 (2019).

\section{Acknowledgements}

This study was supported by Grant-in-aid for scientific research from the National Natural Science Foundation of China (No. 11772038).

\section{Author contributions}

X.S. designed the study, J.B. performed the data analysis and wrote the manuscript. Y.B. performed the debugging and measurement of experimental parameters and collected data. L.Y. and Q.X. revised the manuscript. All authors reviewed the manuscript.

\section{Competing interests}

The authors declare no competing interests.

\section{Additional information}

Correspondence and requests for materials should be addressed to X.S.

Reprints and permissions information is available at www.nature.com/reprints.

Publisher's note Springer Nature remains neutral with regard to jurisdictional claims in published maps and institutional affiliations. 
(c) (i) Open Access This article is licensed under a Creative Commons Attribution 4.0 International cc) License, which permits use, sharing, adaptation, distribution and reproduction in any medium or format, as long as you give appropriate credit to the original author(s) and the source, provide a link to the Creative Commons licence, and indicate if changes were made. The images or other third party material in this article are included in the article's Creative Commons licence, unless indicated otherwise in a credit line to the material. If material is not included in the article's Creative Commons licence and your intended use is not permitted by statutory regulation or exceeds the permitted use, you will need to obtain permission directly from the copyright holder. To view a copy of this licence, visit http://creativecommons.org/licenses/by/4.0/.

(C) The Author(s) 2021 